\title{
AVALIAÇÃO DOS RECURSOS NATURAIS NA ILHA DA INHACA (OCEANO ÍNDICO, MOÇAMBIQUE): PRIMEIRA APROXIMAÇÃO
}

\author{
EVALUATION OF NATURAL RESOURCES IN THE INHACA ISLAND \\ (INDIAN OCEAN, MOZAMBIQUE): FIRST APPROACH
}

ÉVALUATION DES RESSOURCES NATURELLES SUR ÎLE D`INHACA
(OCÉAN INDIEN, MOZAMBIQUE): PREMIĖRE APPROCHE

Inocêncio J. J. F. Pereira - Eduardo Mondlane - Moçambique

Inocêncio.pereira@gmail.com

Flávio Rodrigues do Nascimento - Universidade Federal Fluminense - Niterói - Rio de Janeiro - Brasil
flaviogeo@bol.com.br

\section{Resumo}

Este artigo avalia o estado de degradação ou conservação da terra na llha da Inhaca, a partir de uma proposta teórica de degradação da terra e com apoio em geotecnologias. A degradação da terra é concebida como processo de mudanças ordenadas na estrutura e funções da paisagem. Uma parcela de terra é então susceptível à desertificação quando aspectos do suporte geoambiental, particularmente as condições hidrogeológicas são afetadas por fenômenos de degradação (como por exemplo, a diminuição do nível dos lençóis freáticos, seja por conta de variação climática, seja por exploração excessiva dos recursos hídricos subterrâneos). A llha da Inhaca não é susceptível à desertificação, porém, a degradação da vegetação e do solo é localmente preocupante.

Palavras-chave: Ilha da Inhaca, degradação da terra, susceptibilidade à desertificação.

\section{Abstract}

This article assesses the state of land degradation or conservation in Inhaca Island, based on a theoretical proposal process of land degradation and with support of geo-technologies. Land degradation is conceived as a process of ordered changes in the structure and functions of the landscape. A portion of land is then susceptible to desertification when aspects of geo-environmental support, particularly hydrogeological conditions, are affected by degradation phenomena (such as the decrease in the level of groundwater due either to climatic variations or to over exploitation of groundwater resources). The Inhaca Island is not susceptible to desertification, however, degradation of vegetation and soil is locally of great concern. Keywords: Inhaca Island, land degradation, susceptibility to desertification.

\section{Résumé}

Cet article évalue l'état de dégradation et la conservation des terres dans l'île d'Inhaca, à partir d'un processus théorique proposée de la dégradation des terres et avec l'appuie dans la géotechnique. La dégradation des terres est conçue comme un processus de changements ordonnés dans la structure et les fonctions du paysage. Une parcelle de terrain est alors sensible à la désertification lorsque les aspects du soutien géoenvironnementaux, particulièrement quand les conditions hydrogéologiques sont touchés par les phénomènes de dégradation (comme la baisse du niveau des eaux souterraines due aux variations climatiques, que ce soit par la surexploitation des ressources eaux souterraines). L'île d'Inhaca n'est pas sensible à la désertification, cependant, la dégradation de la végétation et le sol est localement préoccupante.

Motsclés: Île Inhaca, dégradation des terres, sensibilité à la desertification 
Introdução

A partir de uma proposta de avaliação da degradação da terra, com apoio em geotecnologias, avalia-se o estado de degradação ou conservação da terra na Inhaca, uma pequena ilha situada no Oceano Índico, mais precisamente na Baía de Maputo, Moçambique. A Ilha da Inhaca está situada a $32 \mathrm{~km}$ defronte da Cidade de Maputo - a capital da República de Moçambique. Possui uma área total de cerca de $42 \mathrm{~km}^{2}$, e é a maior das duas ilhas que formam o Arquipélago da Inhaca, sendo a outra, a Ilha dos Portugueses. Situa-se no quadrante dos paralelos $25^{\circ} 57^{\prime} 49^{\prime \prime}$ e e $26^{\circ} 05^{\prime} 00^{\prime \prime} S$ e meridianos 3253’00”E e 3300’00” E.

Inhaca é aculturação de Nhaca, do nome de Tsonga Nhaca, o chefe que habitou em Maputo por volta do século XVI e cuja dinastia (a dinastia Nhaca) deu nome à ilha. Recentemente, o Conselho Municipal deliberou designar Ka-Nhaca (literalmente significando "De Nhaca” em Ronga, uma língua local) o Distrito constituído pelo Arquipélago. Do ponto de vista político-administrativo, a Ilha da Inhaca pertence à região sul de Moçambique, Município de Maputo e integra o Distrito Municipal Ka-Nhaca, o qual encontra-se dividido em três bairros, a saber, Ribjene, Inguane e Nyakeni. A Ilha dos Portugueses, fazendo parte deste Distrito Municipal, não é habitada (Figura 1).

A forma física da Ilha da Inhaca, lembrando a letra $\mathrm{N}$ italicizada, destaca três saliências (Ponta Ponduíne, Ponta Torres e Ponta Mazonduè) e uma reentrância ou enseada (Saco da Inhaca) de tal sorte que, como Sénvano et al. (1997) indicam, os lugares mais afastados um do outro na Ilha da Inhaca, a Ponta Torres e a Ponta Mazonduè, estão separados por uma distância de $13 \mathrm{~km}$, e a largura máxima, de $6,5 \mathrm{~km}$, vai desde a Barreira Vermelha à costa leste.

Não obstante, Glantz e Orlovsky (1983) avaliaram numerosas definições do termo "degradação da terra" e concluíram que este termo é geralmente visto como um processo de mudança. Blaikie e Brookfield (1994:17) ilustraram que a degradação é também um termo perceptual: o que um utilizador atual ou potencial da terra pode considerar como alterações benéficas na qualidade de terra podem ser consideradas prejudiciais por outro. 
Figura 1- A ilha da Inhaca e sua posição na República de Moçambique

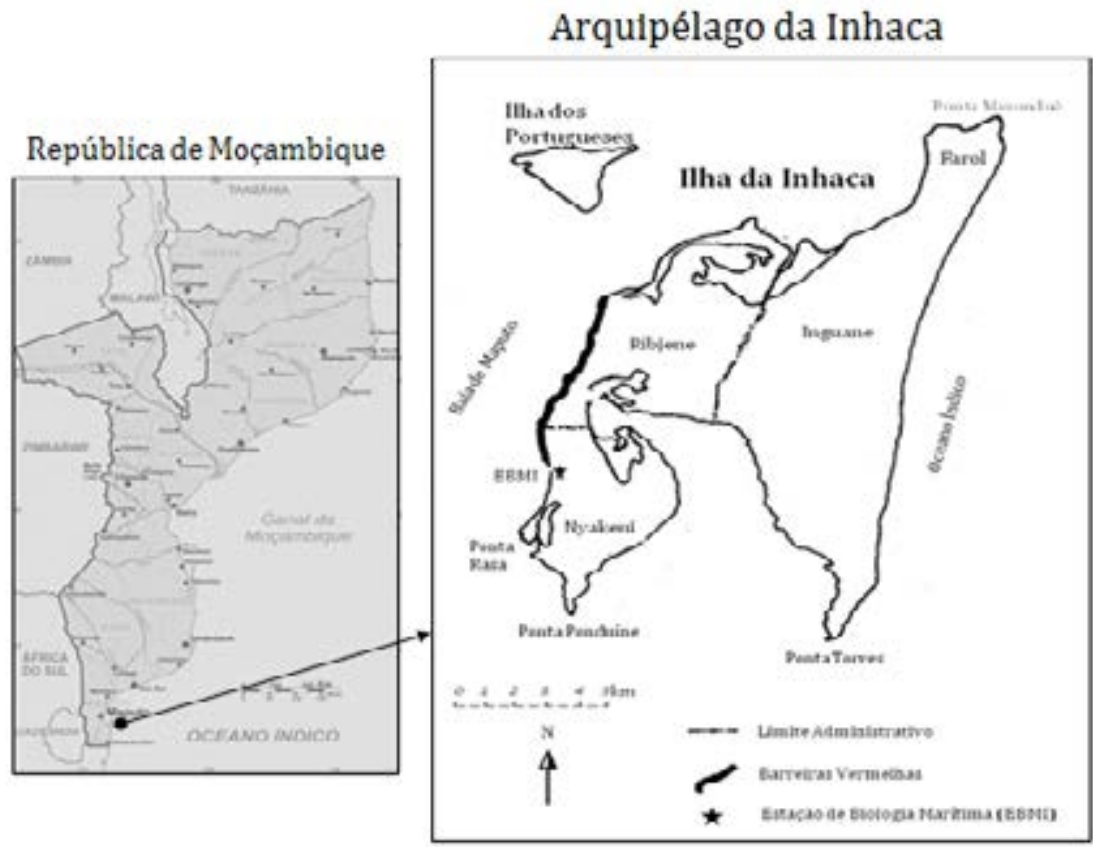

A degradação da terra é aqui concebida como processo de mudanças ordenadas na estrutura e funções da paisagem. Uma parcela de terra é então susceptível à desertificação quando aspectos do suporte geoambiental, particularmente as condições hidrogeológicas são afetadas por fenômenos de degradação (p.ex. a diminuição do nível dos lençóis freáticos, seja por conta de variação climática, seja por exploração excessiva dos recursos hídricos subterrâneos). Neste contexto, o estudo iniciou-se a partir da avaliação bibliográfica sobre a Ilha de Inhaca e observações efetuadas recentementesobre a mesma, relacionadas com aspectos da degradação da terra. Com efeito, estudos recentes não dão indicações claras sobre degradação da terra na Inhaca: segundo Zorini et al. (2004) e Taylor et al. (2003), os mangais da Inhaca são explorados para as necessidades domésticas e a pressão sobre as florestas ainda é ecologicamente sustentável, tanto que, como referem Zorini et al. (2004) e UEM (2007), o padrão de uso dos mangais para autoconsumo é fortemente definido por suas fracas ligações com o continente e inexistência de transporte dentro da ilha. 
Contudo, alertas sobre degradação ambiental ou risco de degradação persistiram durante as últimas três décadas, sobretudo acometendo a degradação da vegetação e do solo. Especialmente as vegetações de mangue e das Reservas Florestais forammuitas vezes indicados como comprometidas em sua existência e manutenção ecossistêmica (UEM, 1976; CNPF, 1990; Barbosa, 1995; Moreira, 2005; Muacanhia et al, 2008; Chongo, 2008; UEM, 2009). Pode-se mesmo argumentar que a Sessão do Conselho de Ministros realizada em 14 de Julho de 2009 aprovou a criação da Reserva Marinha Parcial da Ponta do Ouro, abrangendo o Arquipélago da Inhaca (Quadro 1), resultado da sensibilidade governamental sobre o estado de conservação da região e sua importância no futuro. O interesse científico pela Ilha da Inhaca não é recente, sendo rastreável até pelo menos os princípios do século passado, quando da estada na Ilha do botânico do Imperial College (Londres) em 1909; da qual se seguiu, em 1922, a conhecida expedição conjunta luso/britânica/ sul-africana que produziu um primeiro levantamento florístico, ictiológico, entomológico, malacológico e geológico.

Quadro 1- Cronologia legislativa, Arquipélago da Inhaca

\begin{tabular}{|c|c|}
\hline INSTRUMENTO LEGAL & EFEITOS \\
\hline $\begin{array}{c}\text { Diploma Legislativo Número 2375, de } 4 \\
\text { de Maio de 1963, I Série }\end{array}$ & $\begin{array}{c}\text { Integra a Estação de Biologia Marinha da Inhaca no Instituto de } \\
\text { Investigação Científica de Moçambique }\end{array}$ \\
\hline $\begin{array}{c}\text { Portaria Número 18736, de } 5 \text { de Junho } \\
\text { de 1965, I Série }\end{array}$ & $\begin{array}{c}\text { Determina a delimitação dos terrenos das Ilhas da Inhaca e dos } \\
\text { Portugueses e atribui a sua gestão ao Instituto de Investigação } \\
\text { Científica de Moçambique }\end{array}$ \\
\hline $\begin{array}{c}\text { Diploma Legislativo Número 2620, de } \\
\text { 24 de Julho de 1965, I Série }\end{array}$ & $\begin{array}{c}\text { Cria a Reserva Parcial da Ilha da Inhaca, dentre as áreas cuja gestão } \\
\text { estava confiada ao Instituto de Investigação Científica de Moçambique }\end{array}$ \\
\hline $\begin{array}{c}\text { Decreto Número 30/75, de 23 de } \\
\text { Outubro, do Conselho de Ministros }\end{array}$ & $\begin{array}{c}\text { Integra o Instituto de Investigação Científica de Moçambique na } \\
\text { estrutura administrativa da Universidade de Lourenço Marques }\end{array}$ \\
\hline $\begin{array}{c}\text { Decreto Número 12/1995 de 25 de } \\
\text { Abril, do Conselho de Ministros }\end{array}$ & $\begin{array}{c}\text { Altera a designação da Universidade de Lourenço Marques para } \\
\text { Universidade Eduardo Mondlane e Aprova os Estatutos da Universidade } \\
\text { Eduardo Mondlane }\end{array}$ \\
\hline $\begin{array}{c}\text { XIV Sessão do Conselho de Ministros } \\
\text { realizada a 14 de Julho de 2009 }\end{array}$ & $\begin{array}{c}\text { Aprova a criação da Reserva Marinha Parcial da Ponta do Ouro, } \\
\text { abrangendo o Arquipélago da Inhaca }\end{array}$ \\
\hline
\end{tabular}

O prestígio da Ilha da Inhaca estende-se desde a sua importância ecológica no abrandamento dos fluxos da corrente marítima do Oceano Índico e como centro de atração para investigação e educação, ecoturismo e turismo científico e mesmo como patrimônio biológico, modelo em miniatura de toda a costa moçambicana, segundo Lopes (2009), com 
representantes de todos os habitats, ecossistemas e recursos marinhos existentes no país inteiro.

A população da Ilha da Inhaca vive da agricultura, exploração de recursos florestais (incluindo dos manguezais) e da pesca. As florestas, por exemplo, são usadas como fonte de vários produtos madeireiros e não madeireiros: a população da Inhaca retira das florestas lenha, frutos silvestres, medicamentos, materiais de construção entre outros produtos. Vastas áreas de florestas são convertidas anualmente para agricultura (Bandeira, 1991; Barbosa, 1995). Os agricultores retiram também a camada superficial do solo nas florestas, enriquecida de material orgânico vegetal, para aplicar na agricultura familiar - de que se sabe ser ainda assim de rendimentos baixos (Campbell et al., 1988; Serra King, 1995). Esta prática é realizada porque, o cultivo permanente dos campos agrícolas, frente à ausência de práticas de rotação de culturas, tende a aumentar o consumo de nutrientes do solo e a esgotar a capacidade biológica de produção; os agricultores têm de tentar manter o teor de matéria orgânica elevado nos solos, na medida em que é viável em termos econômicos e práticos. Sem prática de reposição de fertilizantes naturais pode ocorrer uma rápida diminuição de matéria orgânica nos solos e consequentemente mudanças em outras propriedades físicas e químicas.

\section{A Ilha da Inhaca}

\section{Geologia e geomorfologia}

As formações geológicas que ocorrem na Inhaca datam do Pleistocênico Médio-Superior ao Recente. Consistem de várias gerações de dunas e depósitos marinhos costeiros. Estas formações estabeleceram um relevo ondulado, com as formas convexas constituídas por dunas antigas e recentes - a maior parte das dunas antigas estão fixadas e,das dunas recentes, uma parte encontra-se em remobilização - e formas côncavas consistindo de vales interdunares, paleoplanícies tidais, planícies intertidais e barras de areia (Sénvano et al., 1997; Ing, 2007).

As dunas antigas se erguem no lado ocidental da Inhaca até 66 metros de altitude no Alto Pocuane e se estendem predominantemente na direção SSW-NNE à semelhança da disposição das dunas do lado oriental, da Ponta Mazonduè até à Ponta Torres. Estas, porém, são mais 
elevadas se destacando a duna que constitui o Monte Inhaca, com 115m de altitude. A área central é uma superfície ondulada, com cotas máximas na ordem dos $35 \mathrm{~m}$ e a parte norte são paleo planícies tidais e supratidais (Sénvanoop Cit., 1997).

A costa da Ilha da Inhaca está em recuo, na latitude do Monte Inhaca, estimando Moreira (2005) em $0,11 \mathrm{~m} / \mathrm{ano}$ e a praia alta teria emagrecido $22 \mathrm{~m}$, a uma taxa anual de erosão de 0,81m, entre 1973 e 1999. A porção costeira meridional, à latitude da Ponta Torres, consiste de planícies intertidais e praias, donde se levantam dunas que localmente ultrapassam 40m de altitude, com uma cobertura de vegetação de floresta (op. cit.).

\section{Clima e hidrologia}

O clima da Inhaca é tropical úmido moderado, com as duas estações distintas (Sénvano et al., 1997): a estação fresca e secaque vai de Abril a Setembro e a outra, quente e úmida, de Outubro a Março. Os meses de Janeiro e Fevereiro são os mais quentes e chuvosos, com temperaturas de $26,3^{\circ} \mathrm{C}$ e $26,2^{\circ} \mathrm{C}$ e precipitação de $135,9 \mathrm{~mm}$ e $143,9 \mathrm{~mm}$, respectivamente. A precipitação mensal mais baixa é de $23,7 \mathrm{~mm}$ e registra-se durante o mês Agosto, enquanto a temperatura média mensal mais baixa é de $19,6^{\circ} \mathrm{C}$ e ocorre em Julho. A direção predominante do vento é Sudoeste, mas de Outubro a Janeiro prevalece a direção Nordeste. A umidade relativa mais alta atinge $82,1 \%$ e a evaporação, de variações moderadas, alcança em média 100mm/mês (Mavume, 2000). A corrente quente do Canal de Moçambique, que banha a Ilha, e a insularidade são os principais responsáveis pelo relativo aumento de umidade (Sénvano et al., 1997).

Sem curso de água doce nem mesmo que vá dar ao mar (CNPF, 1990:27) e com formações lacustres apenas de pequena dimensão e terras úmidas (lagunas) relativamente extensas, a drenagem em Inhaca é somente interna, perdendo a umidade por evapotranspiração e ganhando-a com a precipitação. Esta circulação da água está ligada ao mar de que a terra firme de Inhaca recebe influência, e é definida, em grande medida, por aspectos geo-hidrológicos também (Muacanhia et al., 2008).

$\mathrm{Na}$ Inhaca, os solos das dunas são arenosos em textura, brancos em coloração e pobres em fertilidade cobrindo uma área de 3000 ha. São solos profundos e muito permeáveis. Nas partes mais baixas, sob evidente 
influência hídrica, se localizam solos cuja gênese foi determinada pela influência principal da topografia baixa e da drenagem deficiente. Assim, a variação espacial dos solos na Inhaca se deve essencialmente à topografia e às condições de drenagem interna. Com efeito, Engelen e Kauffman (1977) distinguiram na Inhaca solos das dunas, os hidromórficos de laguna com água doce e aqueles hidromórficos salgados.

Os solos hidromórficos de laguna com água doce, pelo contrário, abundam nas terras úmidas onde o lençol freático não é profundo e com propensão à inundação ou pelo menos ao alagamento. Em cor, variam de branco a cinzento, os desta última cor são comuns nas margens das lagoas. A ocorrência de solos hidromórficos salgados, porém, coincide com as áreas mais planas, que recebem influência notável de águas salobras (Engelen e Kauffman, 1977). Segundo Muacanhia et al (2008), a possibilidade de intercâmbio da água doce com a água salgada do mar é acentuada durante as marés vivas, e, por esta razão, a profundidade do lençol freático doce sofre mobilidade e variação em salinidade.

\section{Vegetação e fauna}

A vegetação e fauna de Inhaca consistem de espécies terrestres e aquático-marinhas. A vegetação natural terrestre da Inhaca está correlacionada com as condições edafo-climáticas da terra firme. As atividades humanas são responsáveis pelas modificações na cobertura vegetal da ilha: nas terras cultivadas e na área urbana, a cobertura pela vegetação natural foi substituída por culturas alimentares e plantas de ornamentação. Nas Reservas Florestais, porém, a vegetação natural está quase intacta e os mangais da Inhaca, em muitos lugares, estão notavelmente degradados enquanto em outros, menos acessíveis aos usos humanos,parece vegetação primária nunca perturbada.

A classificação da vegetação da Ilha, segundo Kalk (1995) não considera esta influência humana. Também não se baseia em um único critério para toda área insular. Ela usa critérios fisionômicos, designado critério geográfico de localização. Kalk (op Cit) identificou os seguintes tipos ou formações de vegetação: floresta costeira, brenha costeira, mata, vegetação das planícies de inundação e vegetação pioneira.

A floresta costeira da Inhaca predomina sobre as dunas da costa Oriental e junto às Barreiras Vermelhas, na parte Ocidental da Ilha. Na 
imagem de satélite QuickBird (2012), a ocorrência de florestas costeiras é distinta pela cor verde-carregada cobrindo áreas relativamente extensas, porém salpicadas por manchas de verde-pálido de pequena dimensão. A faixa desde o extremo Sul da Ponta Torres até ao Farol da Inhaca, conforme constatação de Kalk (1995) e observações atualizadas em 2009, forma uma das poucas porções da ilha com ecossistema de floresta de baixa perturbação por atividades humanas. As matas caracterizam-se por possuir árvores dispersas separadas entre si por extensas áreas de graminal associado ou não a arbustos pequenos (Kalk, ibid). Pelo contrário, a vegetação pioneira forma tapete de espécies herbáceas suculentas, ocorrendo imediatamente acima da linha da maré-alta, sobre partículas de areia solta, onde os solos são de baixo teor de matéria orgânica, secos, elevada salinidade e fortes ventos oceânicos.

Por seu turno, a vegetação das planícies de inundação possui uma composição específica típica, consistindo de comunidades quase sempre de caniço (Phragmites australis), e raramente com flora submersa (Kalk, 1995). A sua extensão está correlacionada com as planícies de inundação (dambos): ocupam de 17,5\% da superfície total da Inhaca (Barbosa, 1995). A Inhaca tem a particularidade de se situar perto do limite sul da fauna e flora características de costas tropicais do Leste Africano e ao mesmo tempo em que, é o limite norte da fauna e flora do litoral de Natal e Sudeste da África. A maior parte da fauna e das algas e plantas intertidais marinhos com flores é de origem tropical. Inhaca, à latitude $26^{\circ} \mathrm{S}$, tem os recifes de corais e os manguesos mais meridionais do mundo (Macnaee Kalk, 1962b; Kalk, 1995), reconhecendo-se dois de mangais: um mangal zoneado, associado à água doce e outro ao longo da costa, sem zoneamento.

Marés em Inhaca são tais que, na maré baixa de sizígia, uma grande extensão de praia está exposta. Muitas dessas praias são prados revestidos de gramíneas marinhas que constituem alimento de tartarugas e dugongos, e estes, às vezes, podem ser vistos nos canais ao redor da ilha. Estes prados, na maré baixa, são um terreno de caça interessante de muitos moluscos, equinodermos e caranguejos que se abrigam entre e sob as folhas e caules. Segundo Macnae e Kalk (1962a; 1962b) que conduziram os primeiros estudos da distribuição de animais e plantas nas planícies arenosas e lamacentas expostas na maré baixana Inhaca - uma faixa com uma extensão até cerca de $4 \mathrm{~km}$ da marca de água elevada até ao nível de água baixo - registraram, neste local, aproximadamente 400 espécies de animais. 


\section{Ocupação e uso da terra: breve cenário}

Os primeiros habitantes da Inhaca foram os Tsongas, um povo Bantu que povoava o litoral da Baía de Maputo. Consta que eles teriam entrado através da Península de Machangulo, a Sul. Hoje, a maioria dos habitantes descende de Tsongas é falante de Ronga. Não obstante, em 1970, a Ilha da Inhaca tinha menos de 1.000 habitantes, segundo Moreira (2005). Na década de 80, quando a ilha serviu de refúgio à guerra civil, a Ilha chegou a albergar cerca de 10.000 pessoas (Moreira, 2005). Mais de cinquenta por cento desta população terá regressado às origens, terminado o conflito no continente, em 1992. Com efeito, o censo de população de 1997 recenseou 4.672 pessoas e o de 2007 contou 5.216 pessoas (Araújo, 2005), o que representa um aumento em 544 (10,4\%) pessoas em dez anos.

A economia da Inhacaestá baseada na agricultura familiar, aproveitamentos florestais, pesca artesanal, criação de animais de pequeno porte, comércio e turismo. As principais culturas são o milho, a mandioca, a batata-doce, o amendoim, os feijões (feijão nhemba e feijão jugo), a melancia, a abóbora e a cana-de-açúcar. Também se pratica o cultivo de fruteiras como mangueiras, mamoeiros, coqueiros, citrinos e cajueiros, cujos produtos completam a dieta alimentar e receitas dos produtores.A exploração dos recursos naturais serve às necessidades domésticas e não está sujeito a controle oficial e as pessoas estão autorizadas a cortar árvores para esse fim. No entanto, para evitar a expansão de dunas e consequente perda de florestas e terras agrícolas, não é permitido cortar florestas para fins agrícolas. Segundo Zorini et al. (2004), a colheita de grandes quantidades de produtos naturais não é frequente, pois a falta de transporte limita a demanda. No entanto, a comercialização de peixes, caranguejos e bivalves (Moluscos) é possível e estes bens são trocados por outros produtos trazidos por pessoas que vêm do continente que escalam a ilha.

\section{Metodologia da Pesquisa: Modelo teórico da degradação da terra}

A degradação da terra implica, pelo menos, uma escala de "classificação" de medição relativa, da redução a uma categoria inferior, segundo Blaikie e Brookfield (1994). Estes autores definiram degradação da terra, a partir da perspectiva da Ciência do Solo, como redução da capacidade da terra para suportar um uso particular. A degradação da terra 
consiste em distintos processos de mudançaque afetam negativamente a realização não só da função de produção, mas também das funções relacionadas com meio ambiente, a ocupação humana e economia, segundo a Fao (1995).

Quando se fala de mudança, uma questão importante é também saber o que muda e o fator que ocasiona a mudança. Existe um grande número de aspectos sujeitos à mudança no âmbito da degradação da terra que podem ser agrupados em aspectos relativos ao suporte (condições geológicas, geomorfológicas e hidrogeológicas), ao envoltório (clima e hidrologia de superfície) e à cobertura (solos e condições de biodiversidade). Todavia, osdiversos aspectos ambientais, apesar da sua existência em permanente interação, não mudam em simultâneo e da mesma maneira e intensidade quando sujeitos a modificações pela ação humana. Por outro lado, é importante notar que o sujeito das mudanças na terra é, sobretudo, homem, através da realização das atividades de subsistência. Além disso, quando o homem intervém na natureza, ele não modifica os aspectos geoambientais de forma totalmente arbitrária.

A vegetação é o aspecto da terra mais prontamente acessível ao mais primitivo tipo de operação de uso da terra. O primeiro estágio da degradação antrópica é a interferência na cobertura vegetal, segundo Lima et al. (2010). Tal interferência procede através de atividades ou operações de gestão dos recursos naturais e visam modificar um ou mais aspectos da terra, por exemplo, o solo, a flora/fauna, ou a infraestrutura, segundo De Bie (2000). A atividade humana é dirigida a um aspecto individual ou a um conjunto de aspectos geoambientais. A recoleção de frutos, o corte de lenha, a extração de componentes vegetais com valor medicinal e o carvoeijamento centram-se na vegetação apenas. Elas têm impacto sobre certo número de espécies vegetais (extração seletiva) e resultam na diminuição da densidade da vegetação natural. Pelo contrário, a agricultura requer substituição, em geral, total da vegetação natural, por espécies culturais (eliminação localizada). Quando as operações de uso recaem apenas sobre a vegetação natural, elas não envolvem necessariamente outros aspectos geoambientais. Pelo contrário, quando elas são dirigidas ao solo, como é o caso da atividade agrícola, modificam com as condições geomorfológicas e a hidrologia de superfície, o balanço hídrico do solo, entre outros aspectos. 
Operações de uso que implicam à constituição geológica, tais como a extração de inertes e de outros recursos do subsolo, são ainda mais complexas, pois abrangem praticamente todos os aspectos ambientais. Assim, a degradação da terra aparece como processo gradual de mudanças na estrutura e funções da paisagem que começa com modificações dos aspectos físico-bióticos da cobertura, aprofundando-se com a inclusão do envoltório e do suporte ambiental. Uma vez que as atividades ou operações de gestão da terra envolvidas no uso da terra modificam aspectos da terra, elas podem ser traduzidas por correspondência com os distintos significados de degradação ou de melhoramento da terra que elas representam, deduzido o papel de todas as ações que representem contenção de degradação ou de conservação, se houver.

O Quadro 2 mostra o nível potencial do significado de operações de uso selecionadas. Quando a extração de aquíferos assinala escassez de água eventualmente secas hidrológicas se tornaram comuns; nesse caso, fica-se com a impressão (susceptibilidade) de que a desertificação é necessária (Quadro 2), porém é necessário comprovação científica; tratou-se nas considerações finais deste texto sobre isso.

Quadro 2 - Alterações nas paisagens e riscos de desertificação na Ilha de Inhaca, Moçambique

\begin{tabular}{|c|c|c|}
\hline \multirow{2}{*}{ Cobertura } & Condições de biodiversidade & Operações de uso da terra \\
\cline { 2 - 3 } & Solos & Extração seletiva de espécies vegetais (1) \\
\cline { 2 - 3 } & Clima & Climinação localizada da vegetação (2) \\
\hline \multirow{2}{*}{ Envoltório } & Hidrologivo de superfície & Abstração excessiva de águas superficiais (4) \\
\cline { 2 - 3 } & Condições geomorfológicas & - \\
\hline \multirow{3}{*}{ Suporte } & Condições hidrogeológicas & Extração de aquíferos (5) \\
\cline { 2 - 3 } & Condições geológicas & Exploração mineira (6) \\
\hline & Legenda & (4) Susceptível à desertificação \\
\hline \multirow{2}{*}{ (1) Fenômenos insignificantes de degradação da terra } & (5) Risco de desertificação \\
\hline (2) Fenômenos notáveis de degradação da vegetação & (6) Risco de desertificação \\
\hline \multicolumn{2}{|c|}{ (3) Risco de degradação do solo } & \\
\hline
\end{tabular}




\section{Dados e métodos de análise}

Estudos da degradação da terra usam sistemas de informação geográfica como ferramenta de análise, e, como fontes de dados, produtos provenientes do sensoriamento remoto, observações e medições georeferenciadas no campo, além de dados de fontes bibliográficas.

Quando uma imagem digital obtida por satélite de alta resolução espacial como, por exemplo, QuickBird está disponível, é possível, com apoio de tecnologia de Sistemas de Informação Geográfica, avaliar o estado de degradação ou de conservação da natureza, por meio de operacionalização do conceito de degradação da terra - como processo gradual de mudanças na estrutura e funções da paisagem que começa com modificações dos aspectos físico-bióticos da cobertura, aprofundando-se com a inclusão do envoltório e do suporte geoambiental. Neste estudo, foram usadoso Sistema de Informação Geográfica (SIG) designado Integrated Land and Water Information System (ILWIS 3.3 Academic), a imagem digital do satélite QuickBird (2006) e dados de observações na área de estudo,colhidos em campo quando da preparação do Plano de Manejo e Estratégia de Desenvolvimento da Ilha da Inhaca (UEM, 2009). O modus operandi para atingir os objetivos estabelecidos neste estudo incluiu processamento da imagem digital, destacando-se a classificação supervisionada desta imagem.

a. Classificação da imagem digital: A classificação de imagens do sensoriamento remoto é o processo de extração de informação em imagens para reconhecer padrões e objetos homogêneos (ITC, 2001; Lopes, 2010). Todos os métodos de classificação digital de imagens calculam a média por banda para cada classe de píxeis de treinamento definidos na amostra. O conjunto de médias por classe é chamado de média de classe abaixo - um vetor n-dimensional, formado por $\mathrm{n}$ bandas (De Rosso, 2008).

A classificação digital da imagem de Inhacafoi realizada sobre a composição das três bandas disponíveis por meio da técnica de classificação multiespectral píxel a píxel por Máxima Verossimilhança (Maxver). Baseou-se na construção de conjuntos de treinamento objetivando delinear principais tipos de cobertura da terra.

De acordo com Lopes (2010), os conjuntos de treinamento definem o diagrama de dispersão das classes e suas distribuições de probabilidade, considerando a distribuição de probabilidade normal para cada classe 
do treinamento. Os tipos de uso e cobertura da terra são composições em proporções variadas de aspectos da terra, de píxeis extremamente heterogêneos, sobretudo em imagem de alta resolução espacial, como é o caso da imagem disponível. Para amostragens que permitam construir conjuntos de treinamento de baixa dispersão, foram definidos os seguintes aspectos da terra: árvores, arbustos, gramíneas, culturas e superfícies expostas. Esses aspectos foram posteriormente reclassificados.

Para a classificação por Maxver ser suficientemente precisa é necessário um número razoavelmente elevado de píxeis, para cada conjunto de píxeis de treinamento, segundo Lopes (2010). Para achar as classes relevantes para este estudo que ocorrem na Inhaca (florestas, mata fechada, mata aberta, pântanos, agricultura de sequeiro, agricultura irrigada, solo exposto e dunas expostas), o passo subsequente foi delinear estas unidades, por meio de reclassificação. A floresta, por exemplo, é definida como uma contiguidade de píxeis de árvores (alta densidade de árvores), seja de mangue ou de folha caduca, em número a partir de um patamar (área), podendo haver alguns píxeis correspondentes a arbustos e gramíneas; representa vegetação com predominância de indivíduos lenhosos (Figura 2).

b. Avaliação da precisão da classificação supervisionada da imagem: A classificação supervisionada conta com a separabilidade das classes espectrais (ITC, 2001; DeRosso, 2008). Há várias situações que tornam difícil classificar um píxel: por exemplo, os valores espectrais dos píxeis na borda de duas classes distintas, normalmente influenciados por ambas as classes, são em regra posicionados entre as duas classes e assim, durante a classificação, podem obter do classificador valor indefinido - já que eles não são suficientemente similares a essas classes (De Rosso, 2008).

O forte da matriz de confusão, segundo ITC (2001), é que ela identifica a natureza dos erros de classificação, bem como os seus tamanhos. A classificação foi avaliada por meio de "mapa de confusão", elaborado a partir da "matriz de confusão" (Figura 3).

A Figura 3 resulta da comparação do mapa de uso e cobertura da terra do Plano de Manejo e Estratégia de Desenvolvimento da Ilha da Inhaca (UEM, 2009) e a classificação obtida neste estudo (Figura 2). É de notar que na atual classificação a área construída foi deliberadamente omitida, daí que, no cartograma de confusão essa área aparece como "mal 
classificada”. A Figura 3 também sugere abundância de pântanos. Estas áreas pantanosas constituem as planícies de inundação, consistindo de comunidades vegetais predominantemente de caniço e raramente com flora. Em uma pequena parte, particularmente no sudoeste, não foram corretamente identificados pelo classificador Maxver, provavelmente, em parte, devido à amostragem.

A classificação do uso e cobertura da terra foi sujeita à filtragem para aprimorar o padrão espacial das diferentes classes.

Classificação do estado de conservação/ degradação da terra: O passo final do estudo consistiu na classificação da área de estudo quanto ao seu estado de conservação ou de degradação. Para tal, as classes de uso e cobertura da terra foram convertidas em classes de degradação da terra. A afirmação sobre se uma unidade de terra está realmente em degradação, em risco de degradação ou não se torna atual quando observações de campo, donde se conta aspectos de gestão locais, são devidamente consideradas.

Figura 2 - Classificação do uso e cobertura da terra; Figura 3 - Cartograma de confusão

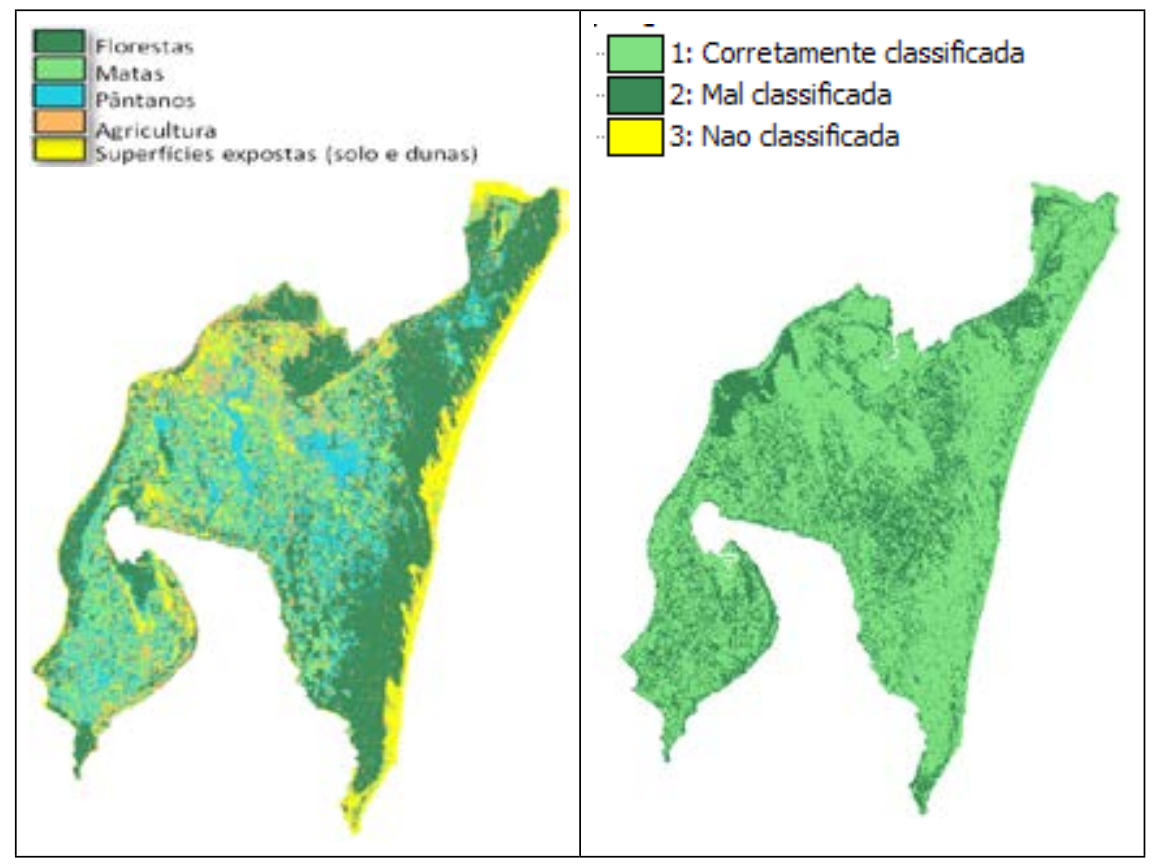


Considerações finais e proposta de pesquisa

A Figura apresenta dados e informações em termos potenciais, do estado de conservação da Ilha de Inhaca. Nota-se que grande parte da Ilha da Inhaca mostra sinais de risco moderado a alto de degradação, localmente com fenômenos de degradação em curso.

As Reservas Florestais da Inhaca não mostram sinais de degradação dignos de preocupação, mas note-se que estas reservas são atravessadas por trilhas frequentadas por quem quer alcançar o mar (não são visíveis no cartograma ou porque não foram captadas pelo classificador, por serem linhas bastante estreitas, ou por que foram reclassificadas durante os passes de filtro). Estas trilhas aproximam pessoas às florestas. Dessa aproximação resulta em parte do risco de degradação da vegetação.

A degradação da terra na Inhaca é do tipo degradação da biodiversidade e localmente dos solos. Embora processos de degradação da terra possam ter simultaneamente causas naturais e humanas, na Ilha da Inhaca a causa é humana. O crescimento vertiginoso da população que decorreu por via da imigração exigiu da Ilha espaço e recursos biológicos. Grande parte da Ilha se apresenta com extensas áreas de gramíneas e arbustos, sobretudo, toda a região central sul, entre as florestas da faixa oriental e os mangais do Saco da Inhaca - resultados do corte da vegetação de floresta aí outrora abundante, para habitação e agricultura. Estas áreas representam provavelmente focos de antigas habitações isoladas e suas áreas agrícolas adstritas. Não estão disponíveis dados da distribuição espacial da população nos anos em que a população da Ilha rondava os 10.000 habitantes. Estas áreas estão hoje praticamente sem população que as habite e sua vegetação em aparente regeneração.

Os instrumentos legais de gestão e proteção da Ilha têm sido de grande importância para o estado atual de conservação da mesma. Com a população naturalmente em crescimento, se torna importante monitorar a pressão social e econômica local sobre os recursos naturais. A redução dessa pressão deve ser acompanhada e sustentada por medidas de redução da pobreza da população local e da sua dependência dos recursos biológicos como acontece até ao presente momento. A ocorrência de determinadas atividades humanas no espaço é bastante para sustentar probabilidade de degradação da terra. 
Quando os aspectos ambientais relativos ao suporte são modificados, os diversos aspectos relativos ao envoltório e à cobertura já sofreram modificações substantivas (degradação), de tal maneira que a área pode ser considerada susceptível à desertificação, e a introdução de medidas de gestão sustentável se torna imprescindível. A susceptibilidade à desertificação de uma área pode ser considerada em face da degradação "moderada" ou mesmo "marginal" do suporte geoambiental, principalmente das condições hidrogeológicas (Quadro 3).

Contudo, estes aspectos atinentes à desertificação, como estudado em Inhaca, estão sendo tratados em segunda aproximação ao tema e ao objeto de estudo, com a elaboração de um texto sobre: Aplicação de geotecnologias no estudo da degradação da terra - Estudo de caso da Ilha da Inhaca, Moçambique /ApplyingGeo-technologies in Land DegradationAssessment in the Inhaca Island, Mozambique. Este texto, a despeito do primeiro, também guarda seu ineditismo.

Figura 4 - Cartograma de Estado de Degradação da Terra, Inhaca

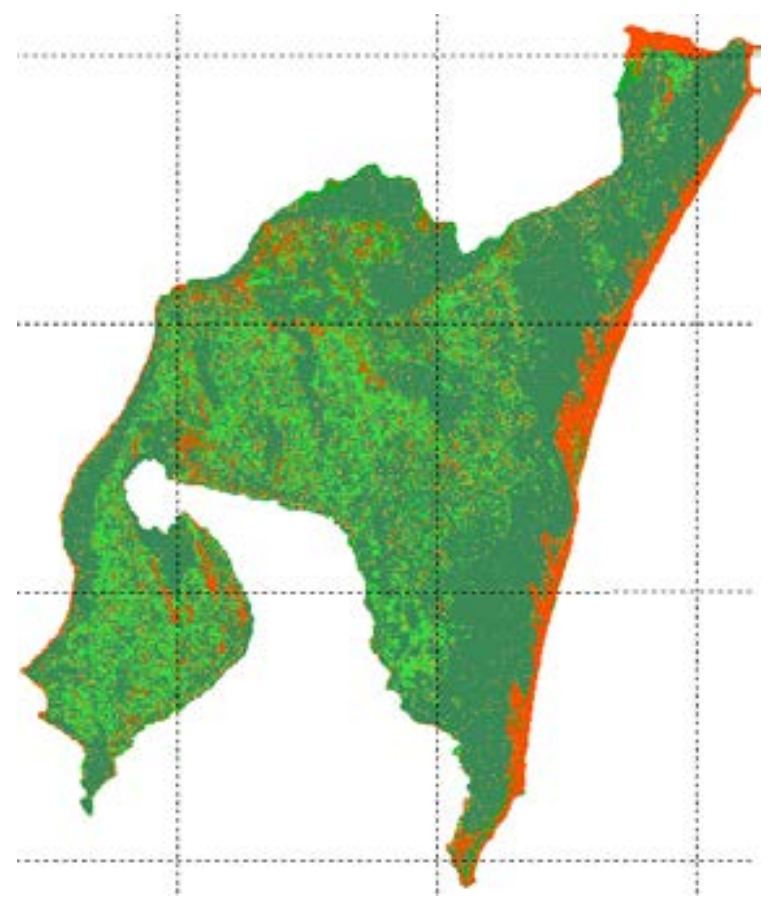


Áreas sem fenómenos significativos de degradaçăo da terra

Áreas com fenômenos marginais a notáveis de degradaçăo da vegetaçăo

Áreas com fenổnenos marginais a notáveis de degradaçẫo da vegetação/

Risco marginal de degradaçæ̋o do solo

Áreas com risco de degradaçaio do solo marginal, moderado ou alto

Áreas com risco de degradaçio do solo e da aggua marginal,

moderado ou alto

Areas com risco de degradação do solo muito alto

Quadro 3 - Modificações na paisagem podem gerar susceptibilidade à desertificação

\begin{tabular}{|c|c|c|c|c|c|}
\hline & TRUTURA DA PAISAGEM & $\cdots$ & $\begin{array}{r}\text { DEGRADA } \\
\text { RISCO DE D }\end{array}$ & $\begin{array}{l}\text { DA TERRA } \\
\text { TIFICAÇÃO }\end{array}$ & $\rightarrow$ \\
\hline 茕 & Condições de biodiversidade & Degrada & oderada & Degrad & Severa \\
\hline 응 & Solos & & & & \\
\hline 으 & Clima & & & & \\
\hline$\frac{2}{ \pm 0}$ & Hidrologia de superfície & & & & \\
\hline 亡 & Condições hidrogeológicas & Degradação & Marginal & Degradação & Moderada \\
\hline$\stackrel{9}{ \pm}$ & Condições geomorfológicas & & & & \\
\hline 号 & Condições geológicas & Sem Fenôme & Degradação & Degrada & larginal \\
\hline
\end{tabular}

Fonte: Elaborado pelos autores

\section{Referências}

ARAÚJO, M. G. M. De. Cidade de Maputo. Espaços Contrastantes: do urbano ao rural. In: 10., 2005, São Paulo. Anais... São Paulo:Universidade de São Paulo, 2005.

BARBOSA, F.M.A. Uma avaliação do valor das árvores para população daIlha da Inhaca. Universidade Eduardo Mondlane. Maputo: Moçambique,1995. 85p.

BLAIKIE, P.; Brookfield, H. Land and Degradation and Society, London: Methuen, 1987. 284p.

Chongo, H. Impacto da prática da agricultura nas reservas florestais da Inhaca. Maputo: Instituto Agrário de Boane. 2008. 19p. 
CNPF- Comissão Nacional do Plano. Plano de desenvolvimento integrado Ilha da Inhaca. Instituto Nacional de planeamento Físico. Maputo, Moçambique, 1990. 156p.

DE BIE, C. A. J. M. Comparative Performance Analysis of Agro-Ecosystems. ITC. 2000. 232 f. Dissertation No. 75, International Institute for Aerospace Survey and Earth Sciences. 2000.

DE ROSSO, R. V. ILWIS 3.4 OPEN Sensoriamento Remoto-Conceitos e Aplicações. 2008. Disponível em http://xa.yimg.com/kq/groups/17314041/1156849602/name/ Ilwis_34_SR.pdf. Cite on $<3$ de ago. 2015>

ENGELEN, J.V.;Kauffman, S. Reconhecimento dos solos da Ilha da Inhaca, utilizando um mapa fisiográfico. Pedologia e drenagem. Maputo: Faculdade de Agronomia- UEM \& Instituto de Investigação Agronómica de MoçambiqueFAO, 1977. 16p.

ING - Instituto Nacional de Geologia. Carta Geológica Nacional. Maputo: Direcção Nacional de Geologia, 2007.

ITC - International Institute for Aerospace Survey and Earth Sciences. ILWIS 3.0 Academic User's Guide. Unit Geo Software Development, Sector Remote Sensing \& GIS, IT Department. Enschede, The Netherlands, May. 2001.

KALK, M. A natural history of Inhaca Island, Moçambique: Witwatersrand University Press, 3rd Edition, 1995. $365 \mathrm{p}$

LOPES, E. S. S. SPRING Básico - TUTORIAL 10 AULAS - SPRING 5.2 Versão Windows e Linux, INPE - Instituto Nacional de Pesquisas Espaciais, São José dos Campos. Novembro. 2010.

MACNAE, W.; Kalk, Margaret The Fauna and Flora of Sand Flats at Inhaca Island, Moçambique. Journal of Animal Ecology, vol. 31, n.1 (February, 1962a), p. 93-128

MACNAE, W.; Kalk, M. The ecology of the mangrove swamps at Inhaca island, Moçambique. Journal of Ecology, vol. 50, no. 1 (February, 1962b), p. 19-34

MOREIRA, M. E. A dinâmica dos sistemas litorais dos Sul de Mocambique durante os últimos 30 anos. Finisterra, v. 40, 79, 2005, p. 121-135

TAYLOR, M.; Ravilious, C.; Green, E. Mangroves of East Africa. Cambridge. UNEP World Conservation Centre UK. 2003. 26 p.

UEM - Universidade Eduardo Mondlane. Plano de Trabalho Integrado da Inhaca: Relatório final da $1^{a}$ fase. Maputo: UEM, 1976. $193 \mathrm{p}$.

UEM - Universidade Eduardo Mondlane (2007): Estação de Biologia Marítima de Inhaca. Universidade Eduardo Mondlane - Faculdade de Ciências,http://www. ebmi.uem.mz/ visto em 22 de Março de 2013.

UEM - Universidade Eduardo Mondlane (2009): Plano de Manejo do Arquipélago da Inhaca 2010 - 2014. Editado por T. Muacanhia, e L. L. Magaia, Maputo, 20 de Outubro de 2009 
ZORINI, O.; CONTINI, C.; JIDDAWI, N.; OCHIEWO, J.; SHUNULA, J.; CANNICCI, S. (2004): Participatory appraisal for community-based mangrove management in East Africa. Wetlands Ecology and Management, 12, 87-102.

Possui Graduação em Geografia pela Universidade de Martin-Luther e Mestrado em Análise e Monitoramento de Sistemas Ambientais pelo International Institute for Aerospace Surveyand Earth Sciences. Atualmente é professor pela Universidade Eduardo Mondlane e Doutorando da Pós-Graduação em Geografia da Universidade Federal Fluminense.

Flávio Rodrigues do Nascimento - Possui Graduação em Geografia pela Universidade Federal do Ceará. Possui Mestrado Mestre e Doutorado em Geografia pela Universidade Federal Fluminense. Atualmente é professor do Programa de Pós-Graduação em Geografia da Universidade Federal Fluminense e professor Visitante do Departamento de Geografia da Universidade Eduardo Mondlane, Maputo, Moçambique e do Programa de Postgrado Multidisciplinar em Ciencias Ambientales de Universidad Autónoma de San Luis Potosí/ México.

Recebido para publicação em 06 de fevereiro de 2016 Aceito para publicação em 12 de março de 2016 